\title{
Erratum to: Cohen's MRI scoring system has limited value in predicting return to play
}

\author{
Bruce Hamilton $^{1,2} \cdot$ Arnlaug Wangensteen $^{1,3} \cdot \operatorname{Rod}$ Whiteley $^{1} \cdot$ Emad Almusa $^{1}$. \\ Liesel Geertsema ${ }^{1} \cdot$ Stephen Targett $^{1} \cdot$ Johannes L. Tol $^{1,4}$
}

Published online: 27 February 2017

(C) European Society of Sports Traumatology, Knee Surgery, Arthroscopy (ESSKA) 2017

\section{Erratum to: Knee Surg Sports Traumatol Arthrosc DOI 10.1007/s00167-016-4403-8}

In the original article, the corresponding author name has been published incorrectly. The correct complete name should be Johannes L. Tol. The original article has been updated accordingly.

The online version of the original article can be found under doi:10.1007/s00167-016-4403-8.

Johannes L. Tol

johannes.tol@aspetar.com

1 Aspetar, Orthopaedic and Sports Medicine Hospital, Doha, Qatar

2 High Performance Sport NZ, Sport Research Institute of New Zealand, Millenium Institute of Sport and Health, Mairangi Bay, Auckland, New Zealand

3 Oslo Sports Trauma Research Center, Department of Sports Medicine, Norwegian School of Sports Science, Oslo, Norway

4 Academic Center for Evidence Based Medicine (ACES), Academic Medical Center, University of Amsterdam, Amsterdam, The Netherlands 